\title{
Histopathological Patterns of Intracranial Tumours at a Tertiary Health Facility in Sokoto, North-West Nigeria
}

\author{
Sahabi Sadiku Malami ${ }^{1}$, Rasheed Mumini Wemimo ${ }^{2,}$, , Abdullahi Kabiru ${ }^{1}$, \\ Adegboye Adeyemi Taiwo ${ }^{3}$, Mohammed Umar ${ }^{1}$, Afolayan Enoch Abiodun ${ }^{2}$, \\ Oluogun Waheed Akanni ${ }^{4}$, Mohammad Shareef Bello ${ }^{5}$, Nasiru Jinjiri Ismail ${ }^{6}$ \\ ${ }^{1}$ Departments of Histopathology, Usmanu Danfodiyo University Teaching Hospital, Sokoto, Nigeria \\ ${ }^{2}$ Department of Histopathology, University of Ilorin Teaching Hospital, Ilorin, Nigeria \\ ${ }^{3}$ Mojitaiwo Data Services and Data Management Executives, Ilorin, Nigeria \\ ${ }^{4}$ Departments of Histopathology, Ladoke Akintola University of Technology, Osogho, Nigeria \\ ${ }^{5}$ Department of Computer Science, Lead City University, Ibadan, Nigeria \\ ${ }^{6}$ Department of Surgery, Usmanu Danfodio University Teaching Hospital, Sokoto, Nigeria
}

Email address:

smsahabii $a$ gmail.com (S. S. Malami), muminirasheed265 a,gmail.com (R. M. Wemimo)

${ }^{*}$ Corresponding author

\section{To cite this article:}

Sahabi Sadiku Malami, Rasheed Mumini Wemimo, Abdullahi Kabiru, Adegboye Adeyemi Taiwo, Mohammed Umar, Afolayan Enoch Abiodun, Oluogun Waheed Akanni, Mohammad Shareef Bello, Nasiru Jinjiri Ismail. Histopathological Patterns of Intracranial Tumours at a Tertiary Health Facility in Sokoto, North-West Nigeria. American Journal of Laboratory Medicine. Vol. 4, No. 6, 2019 , pp. 119-123. doi: $10.11648 /$ j.ajlm.20190406.17

Received: November 18, 2019; Accepted: November 27, 2019; Published: December 17, 2019

\begin{abstract}
Brain tumours are diverse group of primary CNS tumours and secondary neoplasm arising either from the scalp or from haematogenous spread from distant sites with few biologically aggressive tumours in both adult and paediatric age groups. Brain tumours have been classified based on their presumed cell of origin and degree of differentiation as determined by light microscopy and immunohistochemical studies with tumours distinctive tumour biology, treatment and prognosis. A retrospective study of all cases of intracranial tumours seen over a period of 10 years from January 2008 to December 2017 at Department of Pathology, Usmanu Danfodiyo University Teaching Hospital. This is a regional neurosurgical centre situated at Sokoto North-West Nigeria receiving surgical specimens from Birnin Kebbi, Zamfara, Sokoto, and Katsina state. The age, sex, histologic diagnosis, and histologic grading system using the 2007 WHO grading system were retrieved and recorded. This study reviewed 151 patients managed with histology confirmed intracranial tumour (ICTs). Mean age was $28.17 \pm 17.26$ years. The male-to-female ratio was 1.6:1.0. Peak age range was the third decade (21-30years) and accounted for (20.5\%). Primary ICTs accounted for $95.4 \%$ of the cases and metastatic adenocarcinomas accounted for $4.6 \%$ of the diagnoses and all the cases were seen in adults. Meningioma was the most commonly diagnosed intracranial tumours (39.7\%), followed by astrocytoma $(23.2 \%)$, pituitary adenomas $(7.3 \%)$, craniopharyngioma $(11.9 \%)$ and nodular medulloblastoma accounted for $4.0 \%$. The most common histologic subtype of meningioma was psammomatous accounted for $75.5 \%$, followed by meningotheliomatous $18.5 \%$ and the least was transitional $1.3 \%$. The mean age of meningioma was $32 \pm 11.9$ years with age range from $3-58$ years and male to female ratio of $1.4: 1$ and WHO classification of meningioma are stratified into $3 ; 95 \%$ are in grade 1 and $5 \%$ are in grade 11. Meningioma was the most commonly diagnosed intracranial tumours (39.7\%), followed by astrocytoma (23.2\%), pituitary adenomas $(7.3 \%)$, craniopharyngioma (11.9\%) and nodular medulloblastoma accounted for $4.0 \%$. The most common histologic subtype of meningioma was psammomatous accounted for $75.5 \%$, followed by meningotheliomatous $18.5 \%$ and the least was transitional $1.3 \%$ with WHO classification of meningioma are stratified into $3 ; 95 \%$ are in grade 1 and $5 \%$ are in grade 11 .
\end{abstract}

Keywords: Histopathological Pattern, Intracranial Tumour, Meningioma, Glioma, Embryonal Tumours 


\section{Introduction}

Brain tumours are diverse group of primary CNS tumours and secondary neoplasm arising either from the scalp or from haematogenous spread from distant sites. Each of these tumours has distinctive biology, treatment and prognosis. [1] It accounts for $1.6 \%$ of all cancers cases with an estimate of 296,851 new cases and mortality of 241,037 in 2018 GLOBOCAN. [2] They represent some of the most biologically aggressive tumours in both adult and paediatric age groups. Brain tumours have been classified based on their presumed cell of origin and degree of differentiation as determined by light microscopy and immunohistochemical studies. There is increasing evidence that suggests geographical differences in the incidence and distribution of intracranial tumours differences worldwide. [3, 4]. The previous reports have drawn attention to the relatively lower incidences of some types of brain tumours in some parts of Africa when compared to other parts of the world. [5] Earlier publications from Nigeria reported that brain metastasis and astrocytoma were the most common brain tumours among the adult and paediatric age groups, respectively. [6, 7]. The majority of recent reports from sub-Saharan Africa suggest an increasing incidence of meningioma among the brain tumours in the past two decades. [4, 8]. These findings are strikingly different from the Caucasians, where gliomas, especially Glioblastoma multiforme predominate. It has been argued that the results from sub-Saharan Africa concerning the epidemiology of ICTs may have been influenced by factors such as shorter life expectancy, poor hospital attendance habit, socio-cultural factors that may delay patient decision to seek expert care, the dearth of expertise, and relevant facilities needed for proper diagnosis of brain tumours. [3] These factors may give a picture of an apparently low incidence of ICTs.

However, these circumstances have been changing in the past decade with improvements in medical awareness, expertise and neuroimaging facilities have become available in many centres in Nigeria in order to improve diagnosis of asymptomatic brain tumours. [7] The average socioeconomic conditions and lifestyles are also changing. Therefore, these paradigm shifts would help to define the true frequency of ICTs managed in Nigeria. The major aim of this study is to analyse the current distribution of histologically confirmed brain tumours managed in Sokoto North-West, Nigeria, over a decade.

The aims and objectives of this study are:

To determine the age and sex of patients with intracranial tumours.

To determine the histologic subtypes of intracranial tumours over the study period.

To determine varying sites of histologic subtypes of intracranial tumours.

To determine the symptoms of intracranial tumours with respect to histologic subtypes.

\section{Methodology}

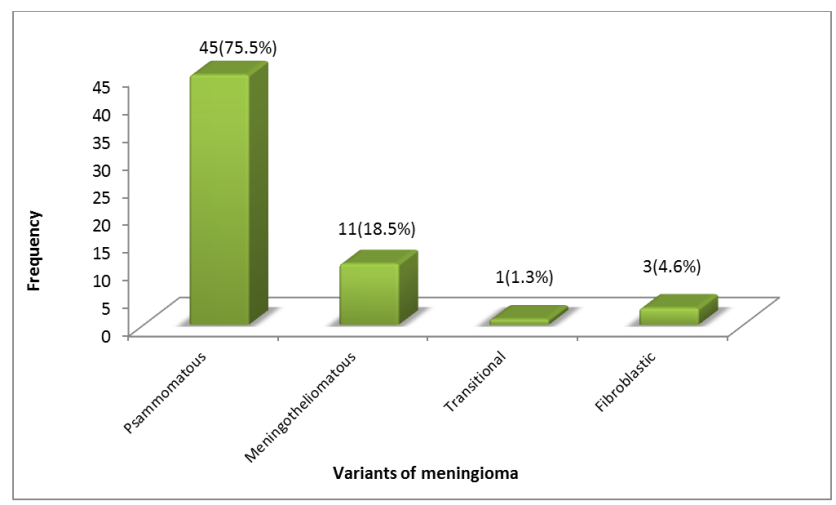

Figure 1. Histological variants of meningioma.

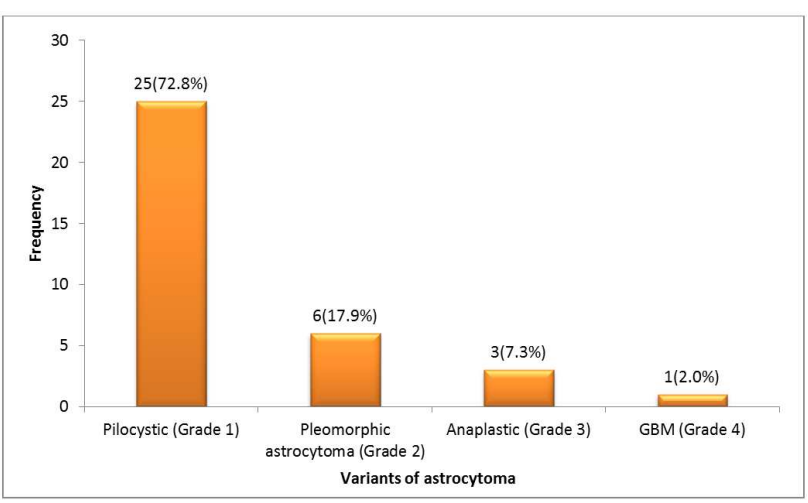

Figure 2. Histological variants of astrocytoma.

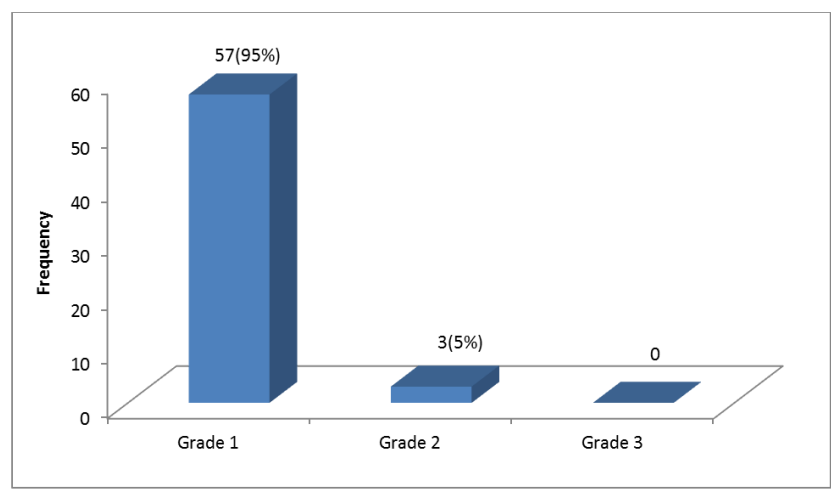

Figure 3. WHO classification of meningioma.

A retrospective study of all cases of intracranial tumours seen was conducted over a period of 10 years from January 2008 to December 2017 at Department of Pathology, Usmanu Danfodiyo University Teaching Hospital. This is a regional neurosurgical centre situated at Sokoto North-West Nigeria receiving surgical specimens from Birnin Kebbi, Zamfara, Sokoto, and Katsina state. The age, sex, histologic diagnosis, and histologic grading system using the 2007 WHO grading system were retrieved and recorded. The cases were classified using the 2007 WHO classification of intracranial tumours. Confidentiality of the identity of the 
patient and personal health information was maintained in strict compliance with the Guideline of the Helsinki Declaration on Biomedical Research on Human Subject. The specimens were processed through fixation, dehydration, clearing and infiltration with paraffin wax. Thin sections (3um) were cut from paraffin-embedded tissue block and stained with eosin and haematoxylin. In rare cases, special stains were used to demonstrate neuroglial cells, reticulin and collagen fibres.

Table 1. Socio-demographic characteristics of patients.

\begin{tabular}{lll}
\hline Variables & Frequency & Percentage \\
\hline Age Groups & & \\
$\leq 10$ & 38 & 25.2 \\
$11-20$ & 19 & 12.6 \\
$21-30$ & 31 & 20.5 \\
$31-40$ & 24 & 15.9 \\
$41-50$ & 24 & 15.9 \\
$\geq 51$ & 15 & 9.9 \\
\hline
\end{tabular}

\begin{tabular}{lll}
\hline Variables & Frequency & Percentage \\
\hline Mean \pm SD & $28.17 \pm 17.26$ & \\
Gender & & \\
Male & 92 & 60.9 \\
Female & 59 & 39.1 \\
\hline
\end{tabular}

Table 2. Diagnosis of intracranial tumour in patients.

\begin{tabular}{lll}
\hline Diagnosis & Frequency & Percentage \\
\hline Meningioma & 60 & 39.7 \\
Astrocytoma & 35 & 23.2 \\
Nodular medulloblastoma & 6 & 4.0 \\
Oligodendroglioma & 3 & 2.0 \\
Pituitary adenoma & 11 & 7.3 \\
Craniopharyngioma adamantinomatous & 15 & 9.9 \\
Ependymoma & 7 & 4.6 \\
Pineoblastoma & 1 & 0.7 \\
Metastatic carcinoma & 7 & 4.6 \\
Atypical teratoid & 3 & 2.0 \\
Ganglioglioma & 3 & 2.0 \\
\hline
\end{tabular}

Table 3. Site of the intracranial tumours.

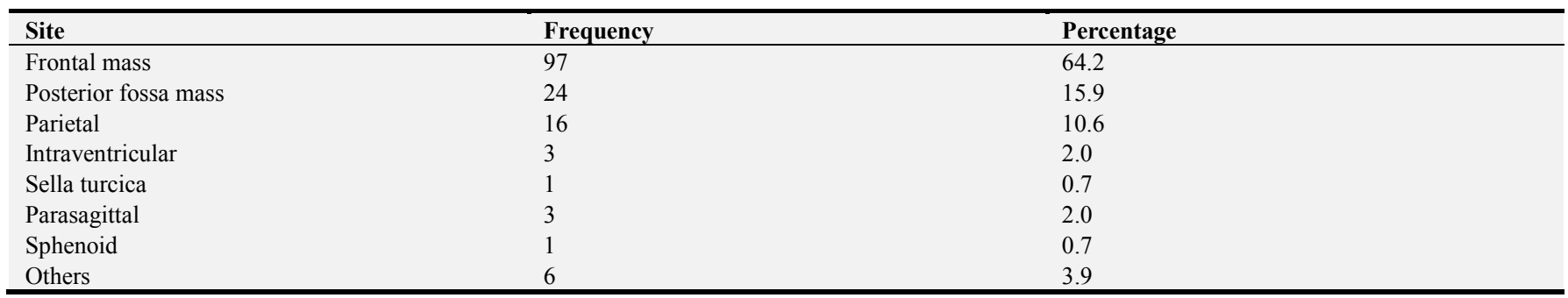

Table 4. Symptoms of intracranial tumours.

\begin{tabular}{llll}
\hline Variables & Frequency & Percentage \\
\hline Headache & 116 & 76.8 & \\
Seizure & 33 & 21.9 & 29.1 \\
Poor vision & 44 & 4.0 & 39.1 \\
Convulsion & 6 & 2.6 & \\
Gait abnormality & 59 & 4 & \\
Others & 4 & & \\
\hline
\end{tabular}

Table 5. Gender and age distribution of intracranial tumour in patients.

\begin{tabular}{|c|c|c|c|c|}
\hline \multirow{2}{*}{ Variables } & \multicolumn{2}{|l|}{ Gender } & \multicolumn{2}{|l|}{ Age } \\
\hline & Male (\%) & Female (\%) & Mean (SD) & Range \\
\hline Meningioma & $35(58.3)$ & $25(41.7)$ & $32.47(11.95)$ & $3-58$ \\
\hline Pilocytic Astrocytoma & $16(45.7)$ & $19(54.3)$ & $14.93(13.08)$ & $0.8-53$ \\
\hline Nodullar medulloblastoma & $2(33.3)$ & $4(66.7)$ & $4.50(3.56)$ & $2-10$ \\
\hline Oligodendroglioma & $1(33.3)$ & $2(66.7)$ & $9.67(6.03)$ & $4-16$ \\
\hline Pituitary adenoma & $10(90.9)$ & $1(9.1)$ & $36.00(17.95)$ & $11-63$ \\
\hline Craniopharyngioma adamantinomatous & $11(73.3)$ & $4(26.7)$ & $32.47(17.14)$ & $9-58$ \\
\hline Pineoblastoma & $1(100.0)$ & $0(0.0)$ & 45 & $45-45$ \\
\hline Metastatic carcinoma & $7(100.0)$ & $0(0.0)$ & $51.43(11.99)$ & $37-68$ \\
\hline Atypical teratoid & $3(100.0)$ & $0(0.0)$ & $25.33(4.04)$ & $23-30$ \\
\hline \multirow[t]{2}{*}{ Ganglioglioma } & $2(66.7)$ & $1(33.3)$ & $25.42(25.33)$ & $3-53$ \\
\hline & \multicolumn{4}{|c|}{$\chi^{2}=11.833, \rho=0.223$} \\
\hline
\end{tabular}

\section{Results}

This study reviewed 151 patients managed with histology confirmed intracranial tumour (ICTs). Mean age was 28.17 \pm 17.26 years. The male-to-female ratio was 1.6:1.0. Peak age range was the third decade (21-30years) and accounted for
(20.5\%). Primary ICTs accounted for $95.4 \%$ of the cases and metastatic adenocarcinomas accounted for $4.6 \%$ of the diagnoses and all the cases were seen in adults. Meningioma was the most commonly diagnosed intracranial tumours $(39.7 \%)$, followed by astrocytoma (23.2\%), pituitary adenomas (7.3\%), craniopharyngioma $(11.9 \%)$ and nodular medulloblastoma accounted for $4.0 \%$. The most common histologic subtype of 
meningioma was psammomatous accounted for $75.5 \%$, followed by meningotheliomatous $18.5 \%$ and the least was transitional $1.3 \%$. The mean age of meningioma was $32 \pm 11.9$ years with age range from 3 - 58years and male to female ratio of 1.4:1 WHO classification of meningioma are stratified into $3,95 \%$ are in grade 1 and $5 \%$ are in grade 11 . The second most common intracranial tumour was astrocytoma which accounted for $23.2 \%$ with mean age of $14.93 \pm 13.08$ years with age range from $0.8-53$ years and male to female ratio of 1:1.2 The commonest histologic subtype of astrocytoma was pilocytic astrocytoma which accounted for $72.8 \%$ and all were found in children, followed by pleomorphic $17.9 \%$, Anaplastic $7.3 \%$ and Glioblastoma mutliforme $2.0 \%$. The most common paediatric tumour was medulloblastoma accounted for $4.0 \%$ with a mean age of $4.50 \pm 3.56$ years, age range from $2-10$ years and male to female ratio of $1: 1.2$. The presentation varied from headache accounted for $(76.8 \%)$, gait abnormality $39.1 \%$, poor vision $29.0 \%$, and seizure\& convulsion $(25.9 \%)$ and other symptoms were abdominal pain, vomiting, dizziness, unconsciousness, hemiparesis, irrational talk, low back pain and inability to walk. The topography varied from frontal which accounted for $64.2 \%$, posterior fossa mass $15.9 \%$, Parietal 10.6\%, and intraventricular 2.0\%, and others $3.9 \%$ (Cerebellopontine angle, Cerebellum, and Abdomen).

\section{Discussion}

This study gives an insight into the current epidemiology of ICTs in North-Western, Sokoto Nigeria. The pattern of patient presentation over the years reveals a progressive increase in the number of patients presenting for surgery with histology confirmed brain tumours. This may be connected with gradual improvement in the level of awareness of brain tumours in the study environment coupled with availability of neurosurgeon centre and improved number of histopathologist in the Teaching Hospital. The increase in the frequency of histology confirmed ICTs may also be an indication that the epidemiology of these tumours is still evolving. In this study, Meningioma accounted for the most frequent diagnosis of all intracranial tumours at $39.7 \%$ followed by Astrocytoma 23.2\%, Craniopharyngioma 9.9\%, and pituitary adenomas $7.3 \%$. The high prevalence of meningioma in our study is in concordance with the findings by Idowu et al, [8] Ibebuike et al [9] in Johannesburg, South Africa, both reported meningioma as the most common brain tumour in their studies and Jibrin et al [10] in Nigeria. This was in agreement with another study conducted by Lee et al [11] in Korea showed meningioma as the commonest tumour $31.2 \%$ followed by astrocytoma $19.4 \%$, and a study by Ghanghoria et al [12] in India showed meningioma as the commonest tumour $41.54 \%$ followed by Astrocytoma $24.61 \%$ among histologic types of intracranial tumours. However, it is in contrast with other studies which show astrocytoma to be the most common intracranial tumour. [1, 7, 13]. There was light male dominance observed in this study which was in concordance with studies by Idowu et al [8] and Majid et al [13]. This was in concordance with a study by Majid et al [11]. Bangladesh and Mohammad et al [14] at Pakistan. However, equal gender distribution (male-female ratio $=1: 1$ ) was in seen in the studies by Soyemi et al [1] and Olasode et al [15]. The peak age group in this study was in 21-30 years accounted for $20.5 \%$ which was in concordance with review by Soyemi et al [1] but in contrast to report by Jibrin et al [10] and Mohammad et al [14] both showed peak age of 41-50 years in the $4^{\text {th }}$ to $5^{\text {th }}$ decade of life. This was in agreement with the study by Majid et al [11]. The earlier age of onset and a large volume of patients recorded in our study might be attributed to accessibility to regional neurosurgical centre in Sokoto, availability of radiological investigations (CT scan and MRI) and histopathologist. The facility serves as the referral centre for patients from Kebbi State, Zamfara State, Katsina State, and neighbouring country Niger Republic. The most common histologic subtype of meningioma in our study was psammomatous accounted for $75.5 \%$, followed by meningotheliomatous $18.5 \%$, fibroblastic $4.6 \%$ and transitional $1.3 \%$ while Soyemi et al [1] reported psammomatous $12.5 \%$, mixed type $37.5 \%$, transitional $25.0 \%$, fibroblastic and meningothelial each account for $12.5 \%$. Abdulrasheed et al [16] reported that meningothelial accounted for $57.75 \%$, fibroblastic $11.11 \%$, transitional $10.43 \%$ and psammomatous $3.84 \%$ in slight agreement with Khalid et al [17] who showed that meningothelial $61.1 \%$, transitional $15.5 \%$, fibroblastic $4.9 \%$ and psammomatous $4.9 \%$. However, Thomas et al [18] showed that transitional accounted for $40.0 \%$, meningothelial $17.0 \%$, fibroblastic $7.0 \%$, psammomatous $0.5 \%$ and angiomatous $1.5 \%$. The discrepancies in the histologic subtype might be attributed to the subjective assessment of histopathological features, lack of strict adherence to WHO diagnostic criteria and paucity of the neuropathologist. Thus, constant improvements in the recent classification system are necessary for the reproducible diagnosis of histologic subtype and grade. Astrocytoma is the second most common intracranial tumour in our study and histologic grade were as follows grade 1 accounted for $72.8 \%$, grade $11,17.9 \%$, grade 111 $7.3 \%$ and grade $1 \mathrm{~V}$ while Ahsan et al [19] showed that Grade I Astrocytoma were $4.9 \%$ followed by $17.8 \%$ of Grade II Astrocytoma, 5.6\% Grade III Astrocytoma and 40.4\% were Grade IV Astrocytoma. Mohammad et al [14] showed that grade 1 was $14.28 \%$, followed by grade 11 $30.30 \%$, grade $11119.00 \%$ and grade IV was $36.30 \%$ with slight agreement in study by Butt et al [20] at Lahore showed combined Grade I and II Astrocytoma 46.3\% followed by Grade III Astrocytoma 21.9\% and Grade IV Astrocytoma $14.6 \%$. In another study conducted by Ahmad et al [21] in Karachi showed Grade I Astrocytoma 15.10\% followed by Grade II Astrocytoma $22.65 \%$ and Grade III and IV combined $60.41 \%$. The variation recorded in the various study may be due to subjective differences in strict adherence to the grading system and paucity of the neuropathologist. 
There is a paucity of literature for the elaborate review of topography and symptoms of patients with intracranial tumours.

\section{Conclusion}

Our findings indicate that meningioma is the most common intracranial tumour in adults, while pilocytic astrocytoma and embryonal tumours are the most common intracranial tumour in children in our environment. The histopathological pattern of intracranial tumours in our environment provides significant information on the behaviour of these tumours. However, inadequate facilities, the dearth of neurosurgeons and resources hamper research. Additionally, genetic researches need to be carried out as they may provide a greater understanding of CNS tumours.

\section{References}

[1] Sunday Sokunle Soyemi and, Olugbenga Olayide Oyewole. Spectrum of intracranial tumours in a tertiary health carefacility: our findings. Pan African Medical Journal. 2015; 20 (24): 1-5.

[2] Freddie Bray, Jacques Ferlay, Isabelle Soerjomataram, Rebecca L. Siegel, Lindsey A. Torre, Ahmedin Jemal. Global Cancer Statistics 2018: GLOBOCAN Estimates of Incidence and Mortality Worldwide for 36 Cancers in 185 Countries. CA Cancer J Clin. 2018; 0 (0): 3-31.

[3] McKinney PA. Brain tumours: Incidence, survival, and aetiology. J Neurol Neurosurg Psychiatry. 2004; 75 (2): 12-7.

[4] Davis FG, McCarthy BJ. Current epidemiological trends and surveillance issues in brain tumors. Expert Rev Anticancer Ther. 2001; 1: 395-401.

[5] Ohaegbulam SC. Geographical neurosurgery. Neurol Res. 1999; 21: 161-70.

[6] Ogun GO. Diagnosis and management of brain tumours at Jos University Teaching Hospital, Nigeria. East Afr Med J. 2001; 78: 148-51.

[7] Chika Anele Ndubuisi, Samuel C. Ohaegbulam, Linda U. Iroegbu, Mike Ezeali Ekuma, Wilfred C. Mezue, and Uwadiegwu Alphonsus ErechukwuHistologically Confirmed Intracranial Tumors Managed at Enugu, Nigeria. J Neurosci Rural Pract. 2017; 8 (4): 585-590.

[8] Idowu O, Akang E, Malomo A. Symptomatic primary intracranial neoplasm in Nigeria. West Afri. J NeurolSci (Turk) 2007; 19 (24): 212-218.
[9] Ibebuike K, Ouma J, Gopal R. Meningiomas among intracranial neoplasms in Johannesburg, South Africa: prevalence, clinical observations and review of the literature. African Health Sciences. 2013; 13: 118-121.

[10] Paul Jibrin, Kaunda Ibebuike, Aisha Nabila Ado-wanka. Histo-pathological pattern of intracranial tumours in the National Hospital, Abuja African Health Sciences. 2018; 18 (2): 281-286.

[11] Lee CH, Jung KW, Yoo H, Park S, Lee SH. Epidemiology of primary brain and central nercous tumors in Korea: J Korean Neurosurg Soc. 2010; 48 (2): 145-52.

[12] Ghanghoria S, Mehar R, Kulkarni CV, Mithal M, Yadev A, Patidar H. Reterospective histopathological analysis of CNS tumors- A 5 years study. International Journal of Medical Science and Public Health. 2014; 3 (10): 1205-7.

[13] Majid N, Ali Z, Rahman MR, Akhter A, Rajib RC, Saha UK. Histological subtypes of brain tumor: pattern in a hospital in Dhaka, Bangladesh. Chatt Maa Shi Hosp Med Coll J. 2013; 12 (1): 9-11.

[14] Mohammad Sajjad, Hamidullah Shah, Zard Ali Khan, Shafi Ullah. Histopathological pattern of intracranial tumors in a Tertiary care Hospital of Peshawar, Pakistan. JSZMC. 2015; 7 (1): 909-912.

[15] Olasode BJ, Shokunbi Mt, Aghadiuno PU. Intracranial Neoplasms in Ibadan, Nigeria. East Afr Med J. 2000; 77: 4-8.

[16] Abdul Rashid Bhat, Muhammed Afzal Wani, Altaf Rehman Kirmani, and Altaf Umar Ramzan. Histological-subtypes and anatomical location correlated in meningeal brain tumors meningiomas. J Neurosci Rural Pract. 2014; 5 (3): 244-249.

[17] Abu Khalid Muhammad Maruf Raza1, Ferdous Ahmed, Tajrin Akter Munni, Zabed Ahmed Mitu, and Shahriar Masood. Histomorphological spectrum of meningioma with variants and grading. Adv Surg Res. 2017; 1 (1): 15-17.

[18] Thomas Backer-Grøndahl, Bjørnar H Moen, Sverre H Torp. The histopathological spectrum of human meningiomas. Int $\mathrm{J}$ Clin Exp Pathol. 2012; 5 (3): 231-242.

[19] Ahsan J, Hashmi SN, Mohammad I, Din HU, Butt AM, Nazir S, Azhar M. Spectrum of CNS tumors- A single center histopathological review of 761 cases over 5 years. JAMC, 2015; 27 (1): 81-4.

[20] Butt ME, Khan SA, Chaudrh NA, Qureshi GR. Intracranial spac occupying lesions A morphological analysis. Biomedica, 2005; 21 (1): 31-5.

[21] Ahmed Z, Kayani MN, Pervez S, Husainy AS, Hasan SH. Histopathological pattern of central nervous system neoplasm. J Pak Med Assoc. 2001; 51 (4): 154-7. 